\title{
Filipino Nurses in Cebu City Reveal High Level of Knowledge, Attitudes, Practices and Willingness in Providing Care to COVID-19 Patients: A Cross-Sectional Analysis
}

\section{Cebu Institute of Medicine \\ Alexandra Astor \\ Cebu Institute of Medicine \\ Joanna Cabrilles \\ Cebu Institute of Medicine \\ Kristiane Codera \\ Cebu Institute of Medicine \\ Edzil Marice Forteza \\ Cebu Institute of Medicine \\ Mugen Ihara \\ Cebu Institute of Medicine \\ Mary Farrah Lagudas \\ Cebu Institute of Medicine \\ Kathleen Kaye Pesante \\ Cebu Institute of Medicine \\ Jae Christelle Tam \\ Cebu Institute of Medicine}

Brian Mortejo Denney ( $\sim$ bmd1333@yahoo.com )

\section{Research Article}

Keywords: Nurses KAP, COVID-19, Willingness to Care, Filipino Nurses, Philippines, Cebu

Posted Date: July 16th, 2021

DOI: https://doi.org/10.21203/rs.3.rs-607473/v3

License: @ (i) This work is licensed under a Creative Commons Attribution 4.0 International License. Read Full License 


\section{Abstract \\ Background}

COVID-19 is a rapidly spreading illness and has resulted in a global pandemic. In the Philippines, active cases of COVID-19 are rising and have threatened both local health and healthcare workers given the limited information on this new disease. Despite several studies conducted to assess the awareness, knowledge, attitude, practices, and willingness of nurses to provide care during this pandemic, there are scarce reports regarding Filipino nurses. Thus, our study assessed such criteria in staff nurses across different Cebu hospitals.

\section{Methods}

This study utilized a descriptive research design using the cross-sectional survey method. A web-based survey and convenience sampling method was adopted to collect the data from Filipino nurses from any hospital in Cebu, of which, 137 participated in the study. A 43-item questionnaire was developed, which was spread out into 5 parts that comprised of the demographic profile, knowledge (15 items), attitude (10 items), practices (9 items), and willingness to care for patients with COVID-19 (9 items). The data was processed and analyzed using inferential statistical tools.

\section{Results}

Majority of the nurses were females (70.80\%), whose ages were $20-25$ years old (54.01\%), single (89.78\%), mostly college degree holder $(90.51 \%)$, and employed in hospitals for $1-3$ years $(64.96 \%)$. They also rely on the internet $(99.27 \%)$ as a source of information related to COVID-19. They also displayed an overall knowledge of $65 \%$ especially about the COVID19 causative agent, its transmission, and pathogenesis. Furthermore, the respondents were generally knowledgeable of the various information regarding COVID-19 at a rate of $79.56 \%$. The mean values for attitude, practices, and willingness to provide care were 4.45 (very favorable), 4.65 (always), and 4.52 (very willing) respectively.

\section{Conclusions}

Generally, the results of our study were favorable across the 5 parts of the survey. Overall knowledge and extent of practice was high, which can be attributed to government efforts of educating healthcare workers and observance of the mandated protocols. In addition, attitude significantly affected the willingness of the nurses to provide care. However, knowledge and practice did not affect the nurses' willingness as the drawbacks and demands of their occupation outweighed and decreased their willingness.

\section{Background}

Coronavirus is known to many as the etiology of the common cold. They are a large family of viruses that can infect a wide range of hosts. But in January 2020, a novel strain of the coronavirus was discovered in China. ${ }^{1}$ This new strain causes a disease currently known as Coronavirus Disease 2019 (COVID-19). This ensued an outbreak in Wuhan, China and in turn resulted in a global pandemic. As of June 2021, there have been over 172 million cases worldwide. From this statistic, approximately 1.2 million cases have been recorded by the Department of Health in the Philippines. In Cebu City, there are a total of 15,759 cases. $^{2}$

Being a developing country, the Philippines' healthcare system is not well-equipped to handle the cases brought about by this pandemic. Although there have been improvements in our healthcare system, there are still many disparities that need to be addressed especially in the regional and socioeconomic aspects. The availability and accessibility of the healthcare 
system is a major problem especially for our current situation. ${ }^{3}$ Various plans of actions have been made and implemented to contain and decrease the impact of the disease, such as expanding of licensed testing laboratories, financing the need for services and the management of a surge of cases needing isolation, quarantine and hospitalization, and addressing the social and economic impact to the community through social amelioration for low income families. But, there is still a misdistribution of resources between urban and rural communities. ${ }^{4}$ Even with the aid from the World Health Organization (WHO), the Philippines is still lacking in various aspects of its healthcare system to control the fluctuating cases of COVID19. More importantly, the healthcare worker to patient ratio is a significant constraint in our country. According to a WHO 2017 review on the Philippine healthcare system, there are 10.4 nurses per 10,000 people in Region VII with Visayas having the highest number of nurses at 2.3 per rural health unit. ${ }^{3}$

COVID-19 has threatened global health and front liners have been doing their part to control it despite the lack of resources and knowledge regarding this new disease. As the surge of infected patients that seek help increases, healthcare workers are faced with the challenge of greater workload and risk of contracting the virus. ${ }^{5}$ Furthermore, the unpredictable course of COVID-19 overwhelms many front liners. In the Philippines, front liners are even more burdened due to the lack of personal protective equipment and other resources that limit their efforts. In addition, Filipino healthcare workers do not get paid enough for the services they offer. ${ }^{6}$ All of this puts a strain in their mental health as they "try to navigate the unprecedented challenges at their workplace" and make difficult decisions under pressure. 5,7

In this study, nurses were the subject because they make up the largest professional healthcare group, "working to identify, isolate, and manage those with COVID-19 and supporting those who have non-COVID-19 related health needs". 8 Therefore, they receive much of the problems during this pandemic since they are one of the first front liners that an individual approaches in the primary healthcare setting. Given this, it is no surprise that nurses are quickly overwhelmed during these times. And to alleviate this problem, other countries have implemented psychotherapy. However, the Philippines struggles to provide the same intervention to its own health workers, who only seek relief from the stress of the pandemic. ${ }^{6}$ While nurses are overburdened, they continue to provide care regardless of the COVID-19 surge and limited knowledge regarding this outbreak.

\section{Research Methodology Study Design and Setting}

This study utilized a descriptive research design using the cross-sectional survey method to identify the level of knowledge, attitude, practices (KAP), and willingness to care for COVID-19 patients of selected Filipino nurses in hospitals in Cebu. A researcher-made validated tool was developed to evaluate KAP of staff nurses on COVID-19 infection and their willingness to care for such patients. Participants were from different tertiary hospitals in Cebu, City Philippines both public and private. The data were analyzed through descriptive and inferential statistics.

\section{Study Population}

The study involved registered Filipino nurses employed in any of the hospitals in Cebu, City Philippines regardless of their employment status. A total of 137 nurses participated in the study. This has a $7 \%$ margin of error with $95 \%$ confidence level to estimate the 545 nurses total population. This study employed a convenience sampling technique as only those staff nurses available and on duty during the data collection period were included.

\section{Research Instrument}

The level of KAP on COVID-19 were assessed using a questionnaire developed by the proponents. A 5-part survey instrument comprised of 43 item questions was developed using the WHO course materials on emerging respiratory viruses including COVID-19 and IATF-DOH Philippine guidelines. 
A pilot study to assess the validity and reliability of the questionnaire was done before its use. Initially, four experts in the field of infectious disease, pulmonology, research and epidemiology from Cebu Institute of Medicine evaluated the questionnaire to assess the degree to which items in the questionnaires were relevant and can correctly measure the KAP and willingness to care of nurses on the subject of COVID-19. The questionnaire was reviewed thereafter and corrections were carried out as per suggestion of the experts. A total of 28 participants participated in the pilot study. The instrument, on the overall, obtained a Cronbach alpha value of 0.83 internal consistency from the items of four domains. The instrument is considered good for implementation.

The first part of the instrument encompassed questions related to the demographic profile of the respondents including gender, age, marital status, educational attainment, and years of service as a hospital nurse.

The knowledge section of the questionnaire consisted of 15 questions: regarding the characteristics of the disease, causative agent, population affected and risk factors, transmission and route of infection, symptoms and clinical manifestations, laboratory detection, possible clinical management, and prevention and control of the disease. Responses to these questions were in the form of a yes, no, or I don't know response. A correct answer was scored 1 point while incorrect answer (including an I don't know response) was scored 0 point. The maximum number of points is 15 and the lowest is 0 . A higher score indicated a better understanding of COVID-19 its mechanisms, pathogenesis, and clinical presentation and management. In this paper, scores 13-15 were considered Very Knowledgeable, 9-12 as Knowledgeable, 5-8 as Less Knowledgeable, and 0-4 as Not Knowledgeable At All.

The attitude domain comprised of 10 questions. The score of the attitude-based questions was a 5-point Likert scale, in which the score of 1 (Strongly Disagree) to 5 (Strongly Agree) was used. The weighted mean was computed to signify the attitude of the respondents where the weighted mean of 1.00-1.79 was considered Very Negative Attitude, 1.80-2.59 as Negative Attitude, 2.60-3.39 as Moderate, 3.40-4.19 as Positive Attitude, and 4.20-5.00 as Very Positive Attitude.

The fourth part evaluated the practices to control and prevent COVID-19 transmission. This section wass comprised of 9 questions. The score of the practice was based on a 5-point Likert scale, in which the score of 1 (Never) to 5 (Always) was used. The weighted mean was computed to signify the attitude of the respondents where the weighted mean of 1.00-1.79 was considered Never, 1.80-2.59 as Seldom, 2.60-3.39 as Sometimes, 3.40-4.19 as Often, and 4.20-5.00 as Always.

The fifth part assessed the willingness to care for patients infected with COVID-19. There were 9 questions in this section. The score was based on a 5-point Likert scale, in which the score of 1 to 5 was given from strongly disagree to strongly agree. The weighted mean was computed to signify the willingness of the respondents where the weighted mean of $1.00-$ 1.79 was considered Not Willing, $1.80-2.59$ as Less Willing, $2.60-3.39$ as Moderate, $3.40-4.19$ as Willing, and 4.20-5.00 as Very Willing.

Finally, the sources of the individuals' information about COVID-19 were recorded. It included social media and the internet, news media (TV/video, magazines, newspapers, and radio), family and friends, scientific journals and articles, as well as health-care providers such as physicians and nurses.

\section{Data Collection Methods}

Data collection was conducted in a 3-week period. Due to stringent lockdown protocols in the country, a web-based survey was used to collect the data. Potential participants were approached via emails and social media groups (Facebook, messenger, etc.). They were requested to fill out the questionnaire via google forms sent through email. A Consent Form and contact number of the researchers were indicated in the first page of the google form. At any point of the process, respondents will be free to ask any questions to the researchers, who at the entire time of data collection, were available via video/phone call. Participation of the respondents was voluntary. Respondents were assured that the information gathered from the survey will be used for research purposes only and that their identities will remain anonymous. A control number 
was assigned to each respondent to ensure confidentiality. Information obtained in this study including personal information of our respondents were kept confidential.

\section{Data Processing and Analysis}

Absolute (n) and relative frequencies (\%) will presented for qualitative variables and mean ( \pm SD) wll be used for continuous variables. Normal distribution will be assessed by the Kolmogorov Smirnov test. Comparison between groups were performed with the use of Pearson-rho moment correlation to test the relationship between the variables of interest. Statistical analysis was performed using the SPSS 16 statistical package (SPSS, Chicago, IL, USA). Statistical significance was defined as $p$ value $<0.05$

\section{Results}

\section{Profile of the Respondents}

Table 1 shows the demographic and work profile of the participating nurses of the administered online survey. Most of these nurses were females (70.80\%), aged 20-25 years old (54.01\%), single (89.78\%) and mostly college degree holders (90.51\%). In terms of the length of working experience, most of the respondents $(64.96 \%)$ had served in hospitals for $1-3$ years while a small proportion (2.92\%) had served for at least a decade.

\section{Sources of Information Related to COVD-19}

In terms of the common sources of information related to COVID-19, Table 2 shows that the internet ranked the top most go to platform (99.27\%). This is followed by social media (83.21\%), the government/health websites such as DOH and WHO (83.21\%) and from the television news (66.42\%).

\section{Level of Knowledge, Attitude and Practices Regarding COVID-19}

\section{Knowledge}

In terms of the know-how of the respondents on COVID-19, Table 3.1 depicts that the overall level of knowledge of the nurses was recorded at $65 \%$. All of the respondents answered correctly on the item "Difficulty breathing, shortness of breath and chest pain are serious symptoms which warrant immediate medical attention". Most were also able to correctly answer "Physical distancing and wearing a mask are effective precautions to prevent spread of the virus" (99.27\%) and "Susceptibility to COVID-19 infection and its severity varies according to the hosts; immune response and comorbid conditions" (97.81\%).

Table 3.2 shows the distribution of respondents in terms of knowledge. As a result, the respondents were generally knowledgeable regarding different COVID-19 related information at a rate of $79.56 \%$. However, approximately $20 \%$ of the respondents who were considered less knowledgeable overall.

\section{Attitude}

Table 4 illustrates the type of attitude the nurses had in terms of the COVID-19 pandemic and related activities. The general attitude of the respondents was very favorable (4.45) to the different events that will help minimize the spread and contamination of the virus. In fact, the items "I am very careful in observing health protocols because I am concerned that I and/or any member of my family might get infected with COVID-19" and "I am willing to comply with all the health protocols mandated by the IATF-DOH" were both rated the highest form of behavior both with a weighted mean of 4.78 . On the other hand, the items "I believe that the severity of the COVID-19 situation in the Philippines will smoothen ", "I am confident to work in the frontlines during this pandemic", "I am confident that I will get full support from my family as a front liner during this pandemic", got the lowest rating in this domain of attitude. 


\section{Practice}

Table 5 reveals the extent of practice of the respondents regarding the COVID-19 measures. In general, they perceived their practice on these items to be Always (4.65). The item "I perform proper hand hygiene after handling patients and/or any contaminated objects" was the most frequent form of practice (4.91). In comparison, the item on "I have been trained on how to handle COVID-19 patients" was only rated with 3.96 .

\section{Level of Willingness to Provide Care to Patients with COVID-19}

As shown in Table 6, generally, the respondents were very willing (4.52) to provide services for the COVID-19inflicted patients. In terms of providing medical care to COVID-19 patients, the willingness to "Prevent spread of infection by adhering strictly to hospital policies of infection control" was rated the highest with 4.87. Likewise, in terms of providing advice and emotional care to COVID-19 patients, the item "Help doctors in educating patients about their condition" and "Become more sensitive to the patients' needs" were also rated highest.

On the other hand, there was a lower score in regards to the extent of willingness when respondents were asked about undertaking the drawbacks as a nurse during the pandemic. In fact, "Work longer hours or extend shift in the hospital if necessary" and "Continue working despite the increased workload and have not considered resignation or other occupation" rated the least in this domain of willingness.

\section{Test of Relationship Between Knowledge, Attitude, Practices and Willingness of the Respondents}

Table 7 provides the extent (coefficient) and the significance ( $p$-value) of the bivariate relationship of interest. Knowledge recorded a p-value of 0.23 , attitude with $p$-value of 0.00 , and practice with $p$-value of 0.35 .

\section{Discussion}

Demographics in research is an independent variable that describes the characteristics of a population being studied..$^{9,10}$ In this case, staff nurses in Cebu Hospitals were the sample population and the demographics taken into account were age, sex, marital status, level of education, and length of working experience, which were relevant to our study. It is no surprise that nurses who spent a longer time serving were only the minority $(2.92 \%)$. This is due to nursing migration that started in the late 1940s to address the shortage of the nursing workforce in the USA. ${ }^{11,12}$ Nursing migration is when nurses in the Philippines are being recruited by developed countries "to maintain acceptable staffing levels". ${ }^{12}$ It was also mentioned that younger Filipino nurses were more likely to have greater intentions of migration than nurses who were 45 years old and above. ${ }^{13}$ Furthermore, a similar study also found out that more than half of Filipino nurses planned to leave the country in 6 months to 2 years. ${ }^{14}$ Workplace stress, low salary, heavy workloads, and lack of professional opportunities also influence nurse migration. ${ }^{13}$ This could explain why the majority of nurses being sampled in our study currently served in their institutions for only $1-3$ years (64.96\%).

Results in this study revealed that the common sources of information to COVID-19 included the internet (99.27\%), social media (83.21\%), government/health websites (83.21\%) and television news (66.42\%). In a similar study, social media (91.1\%) and the websites of hospital/health ministry (82.6\%) were the predominant sources of information regarding COVID-19 for healthcare workers in a hospital in Ho Chi Minh City. ${ }^{15}$ Likewise, the main sources of COVID-19 information for Pakistani nurses were the hospital/health ministry (85.89\%) and social media (60.25\%). ${ }^{16}$ However, social media and the internet are not only sources of information but also of misinformation and conspiracies. which represents a health risk. ${ }^{17,18}$ In addition, "information environment" influences our behaviors and response to COVID-19. ${ }^{17}$ 
Adequate knowledge on COVID-19 causative agent, its pathogenesis, transmission and management are all vital to combat this emerging infectious disease. In fact, the Philippine Department of Health (DOH) has launched several webinars and trainings on handling suspected and confirmed cases. It has created the DOH Emergency Operation Center (DOH EOC) for COVID-19, a command center in-charge of consolidating updates and information as the COVID-19 health event evolves. ${ }^{19}$

It is apparent from Table 3.1 that respondents were most knowledgeable on items about COVID-19 causative agent, its transmission and pathogenesis (items 1 to 6), symptomatology (items 7 to 9), and preventive measures (items 10 and 11). This is to be expected since these domains were covered in nurses' basic competency course training for hospital infection control and handling COVID-19 patients. ${ }^{20}$ On the other hand, majority are less knowledgeable on items referring to clinical and laboratory management (items 12 to 15). Patient clinical management including requisition of correct laboratory workups, medication prescription and recommending plan of treatment are tasks expectedly done by a registered physician and are not part and parcel of nurses' job description. ${ }^{21}$

The respondents with a rate of $79.56 \%$ were generally knowledgeable regarding different COVID-19 related information with minority (20\%) who were considered less knowledgeable overall. This overall knowledge level is relatively higher than the previous studies conducted in Uganda ${ }^{22}$ and $\mathrm{Nepal}^{23}$ at $69 \%$ and $76 \%$ respectively but lower than a study in Henan China where $89 \%$ of the respondents showed adequate knowledge pertaining to COVID-19. ${ }^{24}$ From the data gathered most respondents considered less knowledgeable were those with working experience of less than 2 years. Nurses who worked 3 years or more have a significantly higher score. This is in concordance with previous studies by Khan et al ${ }^{25}$, Hou et a/26, and Wen et $a^{27}$ showing that working experience is associated with KAP scores. The higher the number of years working as a staff nurse, the more knowledgeable and confident the healthcare worker is in dealing with public health emergencies. ${ }^{25-27}$

Patient outcomes and COVID 19 infection control and prevention is directly associated with the knowledge of nurses about the COVID-19 pandemic. ${ }^{28}$ Scarcity of knowledge about this infectious disease escalates the risk of contagion. ${ }^{23,27}$ To note, there is a higher risk among healthcare workers of contracting COVID-19 than the general populace. ${ }^{29}$ Some developed countries have reported considerable rate of infection among healthcare workers like the United States with an infection rate of $16 \%$, Netherlands with $19.6 \%$, Italy with $20 \%$, and Spain with $26 \% .{ }^{30,31}$ A study in Wuhan, China revealed that a lack of special training for nurses in emerging infectious diseases will ultimately lead to poor patient care. ${ }^{28}$ So to speak, it cannot be overemphasized that continuous knowledge update by appropriate trainings or courses are essential as the COVID-19 pandemic evolves.

The general attitude of the respondents was very favorable (4.45) to the different events that will help minimize the spread and contamination of the virus. This very favorable general attitude of the respondents were in agreement with previous studies conducted in China ${ }^{32}$, Nigeria ${ }^{33}$, Ethiopia ${ }^{34}$, Iran ${ }^{35}$, and Saudi Arabia ${ }^{36}$. This finding however, is in contrast to studies in Nepal which showed a less optimistic attitude towards COVID-19 health events. ${ }^{23,37}$ Particularly, respondents were very keen in following health protocols mandated by the government knowing fully that there is a higher risk for health care workers to contracting COVID-19 and for fear of transmitting the infection to family members. Also, COVID-19 policies were strictly implemented by the Interagency Task Force for the Management of Emerging Infectious Diseases (IATF-EID), the agency in-charge for the overall management of COVID-19 preparedness and response in the Philippines. ${ }^{19}$ In addition, participants have a very favorable attitude towards acquiring complete vaccination doses and urging family members and friends to be vaccinated.

As of the time of this writing, the Philippines has reached about 1.25 million recorded cases of COVID-19, ranking second to Indonesia with about 1.8 million recorded cases amongst countries in Southeast Asia with the highest number of COVID-19 cases. ${ }^{38}$ Majority of the respondents had rated lowest on the attitude domain asking if they thought that the COVID-19 situation in the country will smoothen. The researchers believe that this is due to the rising number of active cases in the 
country, despite having a stringent and one of the longest lockdowns in the world. This finding is similar to a previous study in Nepal which revealed that only $50.5 \%$ of the respondents were confident that they could win the battle against COVID-19. ${ }^{37}$ In contrast to studies in China ${ }^{32}$ and Nigeria ${ }^{33}$, participants held a very optimistic attitude towards COVID-19 situation in their country. Confidence to work at the front lines was also rated low by most of the respondents. Being a developing nation, resources are scarce. Our front liners are underpaid. ${ }^{39}$ They battle against fear and anxiety while doing their duty. ${ }^{40}$ Apart from this, they are also burdened with so much pressure from work, stress, insomnia, denial, anger, and fear. ${ }^{41}$ In a similar study in Nepal, health care workers were also less confident in regards to working during this pandemic due to anxiety and fear. ${ }^{37}$

In general, the respondents perceived their extent of practice regarding COVID-19 prevention measures to be Always (4.65) with handwashing the most frequent form of practice (4.91). Proper hand hygiene plays a vital role in preventing disease transmission. Many infections and conditions are spread by not washing hands with soap and clean, running water. ${ }^{42} \mathrm{~A}$ U.S. adult internet survey revealed that the proportion of U.S. adults who remember to wash their hands in certain circumstances is greater during the COVID-19 pandemic than before. ${ }^{43}$ This is supported by previous studies which revealed that during this pandemic majority of health care workers perform proper hand hygiene to prevent spread of infection. ${ }^{23,24,44}$ Our results showed that the respondents of this study have appropriate hand hygiene practices. This finding is of no marvel since the $\mathrm{DOH}$ strictly mandates observance of health protocols in all private and public hospitals in the country. It cannot be overemphasized in this write up that proper hand hygiene is the single most cost-effective measure to deter disease transmission. ${ }^{45,46}$ Furthermore, our data showed that respondents were also careful in observing other health protocols such as wearing of masks upon leaving home and during shifts, proper donning and doffing of PPEs when handling confirmed COVID-19 cases, following hospital infection control measures, avoiding social and large crowd gatherings, and getting tested and participating in contact tracing activities when exposed to confirmed cases.

In comparison, the item on "I have been trained on how to handle COVID-19 patients" was only rated with 3.96. This public health catastrophe befell upon humanity without warning. Little is known about this infectious disease and there is a lack of comprehensive knowledge of the causative agent of this disease, its mechanism of action and clinical symptomatology. In the early phases of the outbreak, Philippines had limited resources and even faced shortage of basic medical supplies such as masks and protective equipment, which hindered the efforts to implement standard protective measures. Not all nurses and other health care workers had the privilege to undergo special training in infectious diseases prior to the pandemic. This finding is consistent with a study in Nepal which revealed that only a few were trained to handle COVID-19 cases (17.5\% out 103 respondents). ${ }^{37}$ Currently, more training sessions have been organized by the WHO, DOH, and private institutions to increase awareness and preparedness.

Generally, the respondents were very willing (4.52) to provide services for the COVID-19- inflicted patients. These findings concur with previous studies conducted in China ${ }^{47}$, Australia ${ }^{48}$, and Bangladesh ${ }^{49}$, where the willingness of nurses to work during this pandemic is significantly high. These findings were also similar to previous studies conducted in China 50 , Australia ${ }^{51}$, Japan ${ }^{52}$, USA ${ }^{53}$, and Taiwan ${ }^{54}$ during the H1N1 influenza pandemic indicating that healthcare workers were willing to extend and render their services to patients in that emergent outbreak. Aside from adhering to infection control measures promulgated by the hospital, the data from Table 6 showed that respondents were also very willing to do essential monitoring and follow-up care to COVID-19 patients by carrying out physicians' orders, taking vital signs, maintaining respiratory functions, administering medications, and the like. They were also very willing to help doctors in educating patients about their condition and offer emotional support to patients and their families. Factors affecting their willingness to provide care were not assessed and will not be discussed in this paper.

On the other hand, there was a lower score in regards to the extent of willingness when respondents were asked about undertaking the drawbacks as a nurse during the pandemic that is, working extended shifts in the hospital and continuing to work despite increasing workload. Health workers had already been experiencing extended shift fatigue even before the 
pandemic hit. ${ }^{55}$ This has been intensified by the current COVID-19 situation. ${ }^{39}$ On top of occupational exposure to the virus, nurses also experience workplace stress and anxiety due to heavy workload and low salary. ${ }^{13,41}$ Nurses who experience emotional burnout often evade taxing situations. ${ }^{56}$ Most ICU nurses experience stress and burnout due to long working hours, frequent night shifts and difficult-to-manage patients. ${ }^{57}$ These might be some of the reasons why most of our respondents are less willing to work for extended shifts and have considered other less demanding jobs during this pandemic. Moreover, studies by Al-Hunaishi et al ${ }^{58}$, Ip et al ${ }^{59}$, Liu et al ${ }^{60}$, and McMullan et al ${ }^{61}$ revealed that the perception of occupational exposure may lead to an unwillingness to go to work, especially when seeing their colleagues acquire the disease. Previous studies also showed a linear correlation of willingness to work and monetary incentives, that is, most are motivated by financial rewards. ${ }^{62,63}$

Table 7 provides the extent (coefficient) and the significance (p-value) of the bivariate relationship of interest. It can be shown that there was no significant correlation between knowledge and practice with the level of willingness ( $p$-value > 0.05). In contrast, Nashwan et al, showed a positive correlation between the level of knowledge and willingness of nurses to work during the pandemic meaning, the higher the level of knowledge of nurses about COVID-19, the more willing they were to work with confirmed COVID-19 patients. ${ }^{64}$ In addition, there was no significant correlation between practice and the willingness to care. However, attitude recorded a p-value of 0.00 (less than 0.05 ) which necessarily translates that there is sufficient statistical evidence in this study to claim that the kind of attitude the respondents had affect significantly their willingness to provide care to covid-19 patients. In fact, the positive coefficient is indicative that as the attitude of the respondents became more favorable, the willingness to care also increased. Wu et al in their study also showed that a favorable attitude correlates directly with willingness to work during this pandemic. ${ }^{65}$

\section{Conclusion}

Generally, the results of our study were favorable across the 5 parts of the survey. Overall knowledge and extent of practice was high, which can be attributed to government efforts of educating healthcare workers and observance of the mandated protocols. Fear of contracting the virus and of transmission also played a role in the general attitude of the respondents. In addition, attitude significantly affected the willingness of the nurses to provide care. However, knowledge and practice did not affect the nurses' willingness as the drawbacks and demands of their occupation outweighed and decreased their willingness. Thus, there should be more efforts to reduce workplace stress and increase salary to motivate nurses to serve the country.

\section{Abbreviations}

- COVID-19 - Coronavirus Disease 2019

- DOH - Department of Health

- IATF-EID - Interagency Task Force for the Management of Emerging Infectious Diseases

- KAP - Knowledge, Attitude and Practices

- SPSS - Statistical Package for Social Sciences

- WHO - World Health Organization

\section{Declarations}

\section{ETHICS DECLARATIONS}

Ethics approval and consent to participate: Ethical Clearance was procured from the Ethical and Review Board (Ref number: 202125) of Cebu Institute of Medicine-Cebu Velez General Hospital in Cebu, Philippines. Participants were asked to check "I agree to participate" before access to questionnaire. 
Consent for publication: Not Applicable

AVAILABILITY OF DATA AND MATERIALS

All datasets supporting the conclusion of this study are included within the article. A raw data may be provided by the corresponding author upon request.

COMPETING INTEREST: The authors declare that they have no competing interests

FUNDING: The study was made possible by researchers' personal funds. No funding associations or body were associated with the study.

\section{AUTHOR INFORMATION}

Affiliation: Cebu Institute of Medicine, Ramos St., Cebu City, Philippines

Contributions: All authors have read and approved the manuscript for publication

BMD: Study conceptualization, development of questionnaire, manuscript preparation, data entry, data collation, final draft approval, final revision. AS: development of questionnaire, manuscript preparation, final draft approval. JC: data entry, data collation, proofreading, final revision, manuscript preparation. KC: data collection, data entry, proofreading. EMF: statistical analysis. MI: data collection, data entry, manuscript preparation. MFL: manuscript preparation, proofreading. KKP: data collation, manuscript preparation. JCT: data collation.

CORRESPONDING AUTHOR: Correspondence to Brian Mortejo Denney

\section{ACKNOWLEDGEMENT}

The researchers are indebted to Dr. Maria Philina Villamor who wholeheartedly helped all throughout the conduct of the study. We would also like to extend our heartfelt gratitude to Mr. Mark Borres, our statistician, for analyzing our data and for his helpful insights on this paper.

\section{References}

1. Coronaviruses. 2020 [cited 2020 Dec 10]; Available from:

https://www.microbiologyresearch.org/content/coronaviruses Department of Health website (doh.gov.ph)

2. Department of health website [Internet]. Gov.ph. [cited 2020 Dec 10]. Available from: https://www.doh.gov.ph/2019$\mathrm{nCoV}$

3. Dayrit MM, Lagrada LP, Picazo OF, Pons MC, Villaverde MC. The Philippines Health System Review. Vol. 8 No. 2. New Delhi: World Health Organization, Regional Office for SouthEast Asia; 2018. (I'm not sure if what citation this is, it just said suggested citation and i'm confused if what category this source is - 9789290226734-eng.pdf (who.int))

4. 100 days of COVID-19 in the Philippines: How WHO supported the Philippine response [Internet]. Who.int. [cited 2020 Dec 10]. Available from: https://www.who.int/philippines/news/feature-stories/detail/100-days-of-covid-19-in-thephilippines-how-who-supported-the-philippine-response

5. Visagie N. Mitigating the psychological and mental health impact on frontline workers during covid-19. Belitung Nurs $\mathrm{J}$ 2020;6:141-2.

6. Biana HT, Joaquin JJB. COVID-19: The need to heed distress calls of healthcare workers. J Public Health (Oxf) 2020;42:853-4.

7. Nyashanu M, Pfende F, Ekpenyong M. Exploring the challenges faced by frontline workers in health and social care amid the COVID-19 pandemic: experiences of frontline workers in the English Midlands region, UK. J Interprof Care

Page $10 / 22$ 
2020;34:655-61.

8. Halcomb E, Williams A, Ashley C, Mclnnes S, Stephen C, Calma K, et al. The support needs of Australian primary health care nurses during the COVID-19 pandemic. J Nurs Manag 2020;28:1553-60.

9. Salkind NJ. Encyclopedia of research design. SAGE; 2010.

10. Connelly LM. Demographic data in research studies. MedSurg Nursing. 2013;22(4):269-270.

11. Choo V. Philippines losing its nurses, and now maybe its doctors. The Lancet. 2003;361(9366):1356.

12. Masselink L, Daniel Lee S. Government officials' representation of nurses and migration in the Philippines. Health Policy and Planning. 2012;28(1):90-99.

13. Labrague L, Gloe D, McEnroe D, Konstantinos K, Colet P. Factors influencing turnover intention among registered nurses in Samar Philippines. Applied Nursing Research. 2018;39:200-206.

14. Lorenzo F, Galvez-Tan J, Icamina K, Javier L. Nurse Migration from a Source Country Perspective: Philippine Country Case Study. Health Services Research. 2007;42(3p2):1406-1418.

15. Huynh G, Nguyen T, Tran V, Vo K, Vo V, Pham L. Knowledge and attitude toward COVID-19 among healthcare workers at District 2 Hospital, Ho Chi Minh City. Asian Pacific Journal of Tropical Medicine. 2020;13(6):260.

16. Alwani S, Majeed M, Ramzan Z, Rauf S, Syed M, Shah S et al. Evaluation of Knowledge, Practices, Attitude, and Anxiety of Nurses towards COVID-19 during the Current Outbreak in Karachi, Pakistan. Pakistan Journal of Public Health. 2021;10(2):82-90.

17. Cinelli M, Quattrociocchi W, Galeazzi A, Valensise C, Brugnoli E, Schmidt A et al. The COVID-19 social media infodemic. Scientific Reports. 2020;10(1).

18. Allington D, Duffy B, Wessely S, Dhavan N, Rubin J. Health-protective behaviour, social media usage and conspiracy belief during the COVID-19 public health emergency - CORRIGENDUM. Psychological Medicine. 2021:1.

19. Department of Health website. [cited 2021Jun5]. Available from: https://doh.gov.ph/COVID-19/FAQs?gclid=Cj0KCQjwGFBhDeARIsACH_kdY-eEWp0RhlgvfX0iJqWTknyrDmJtLxNbz7KHYccqQMItn2tUPOshsaAqTuEALw_wcB

20. Office of the Secretary. Basic Competency Training Course for Infection Control Nurses of the Philippines Hospital Infection Control Nurses Association, Inc. on August 5-9, 2019 Manila, Metro Manila: Department of Health; 2019 p. 1-6.

21. Classen DC, Kilbridge PM. The Roles and Responsibility of Physicians to Improve Patient Safety within Health Care Delivery Systems. Academic Medicine. 2002;77(10):963-72.

22. Olum R, Chekwech G, Wekha G, Nassozi DR, Bongomin F. Coronavirus Disease-2019: Knowledge, Attitude, and Practices of Health Care Workers at Makerere University Teaching Hospitals, Uganda. Frontiers in Public Health. $2020 ; 8$

23. Tamang N, Rai P, Dhungana S, Sherchan B, Shah B, Pyakurel P, et al. COVID-19: A National Survey on Perceived Level of Knowledge, Attitude and Practice among Frontline Healthcare Workers in Nepal. 2020;

24. Zhang M, Zhou M, Tang F, Wang Y, Nie H, Zhang L, et al. Knowledge, attitude, and practice regarding COVID-19 among healthcare workers in Henan, China. Journal of Hospital Infection. 2020;105(2):183-7.

25. Khan MU, Shah S, Ahmad A, Fatokun O. Knowledge and attitude of healthcare workers about middle east respiratory syndrome in multispecialty hospitals of Qassim, Saudi Arabia. BMC Public Health. 2014;14(1).

26. Hou W, Wang HY, Hao JJ, Jin QY, Zhang y. Investigation and analysis on knowledge attitude practice among pediatric healthcare staff of prevention and control and influencing factors of the corona virus disease 2019. Chin J Woman Child Health Res. 2020;31.

27. Wen X, Wang F, Li X, Gu H. Study on the Knowledge, Attitude, and Practice (KAP) of Nursing Staff and Influencing Factors on COVID-19. Frontiers in Public Health. 2021;8. 
28. Jin Z, Luo L, Lei X, Zhou W, Wang Z, Yi L, et al. Knowledge, Attitude, and Practice of Nurses Towards the Prevention and Control of COVID-19. 2020;

29. Nguyen LH, Drew DA, Joshi AD, Guo C-G, Ma W, Mehta RS, et al. Risk of COVID-19 among frontline healthcare workers and the general community: a prospective cohort study. 2020;

30. Papagiannis D, Malli F, Raptis DG, Papathanasiou IV, Fradelos EC, Daniil Z, et al. Assessment of Knowledge, Attitudes, and Practices towards New Coronavirus (SARS-CoV-2) of Health Care Professionals in Greece before the Outbreak Period. International Journal of Environmental Research and Public Health. 2020;17(14):4925.

31. Kassie BA, Adane A, Tilahun YT, Kassahun EA, Ayele AS, Belew AK. Knowledge and attitude towards COVID-19 and associated factors among health care providers in Northwest Ethiopia. PLOS ONE. 2020;15(8).

32. Zhong, B. L., Luo, W., Li, H. M., Zhang, Q. Q., Liu, X. G., Li, W. T., \& Li, Y. Knowledge, attitudes, and practices towards COVID-19 among Chinese residents during the rapid rise period of the COVID-19 outbreak: a quick online crosssectional survey [Internet]. ljbs.com. 2020 [cited 2021 Jun 5]. Available from: https://www.ijbs.com/v16p1745.htm

33. Ejeh FE, Saidu AS, Owoicho S, Maurice NA, Jauro S, Madukaji L, et al. Knowledge, attitude, and practice among healthcare workers towards COVID-19 outbreak in Nigeria. Heliyon [Internet]. 2020 Nov [cited 2021 Jun 5];6(11):e05557. Available from: https://www.cell.com/heliyon/fulltext/S2405-8440(20)32400-2? _returnURL=https\%3A\%2F\%2Flinkinghub.elsevier.com\%2Fretrieve\%2Fpii\%2FS2405844020324002\%3Fshowall\%3Dtrue

34. Tadesse DB, Gebrewahd GT, Demoz GT. Knowledge, attitude, practice and psychological response toward COVID-19 among nurses during the COVID-19 outbreak in northern Ethiopia, 2020. New Microbes and New Infections [Internet]. 2020 Nov [cited 2021 Jun 5];38:100787. Available from:

https://www.sciencedirect.com/science/article/pii/S2052297520301396?via\%3Dihub

35. Nemati M, Ebrahimi B, Nemati F. Assessment of Iranian nurses' knowledge and anxiety toward COVID-19 during the current outbreak in Iran. Archives of Clinical Infectious Diseases [Internet]. 2020 Mar [cited 2021 Jun 5] 15:102848. Available from https://sites.kowsarpub.com/archcid/articles/102848.html

36. Asaad A, El-Sokkary R, Alzamanan M, El-Shafei M. Knowledge and attitudes towards Middle East respiratory sydromecoronavirus (MERS-CoV) among health care workers in south-western Saudi Arabia. Eastern Mediterranean Health Journal. 2020 Apr [cited 2021 Jun 5] 16;26(4):10.26719. Available from https://pubmed.ncbi.nlm.nih.gov/32338362/

37. Limbu DK, Piryani RM, Sunny AK. Healthcare workers' knowledge, attitude and practices during the COVID-19 pandemic response in a tertiary care hospital of Nepal. Sapra A, editor. PLOS ONE [Internet]. 2020 Nov 6 [cited 2021 Jun 5];15(11):e0242126. Available from: https://journals.plos.org/plosone/article?id=10.1371/journal.pone.0242126

38. Southeast Asia Covid-19 Tracker | Center for Strategic and International Studies [Internet]. Csis.org. 2021 [cited 2021 Jun 5]. Available from: https://www.csis.org/programs/southeast-asia-program/southeast-asia-covid-19-tracker-0

39. Biana HT, Joaquin JJB. COVID-19: The need to heed distress calls of healthcare workers. Journal of Public Health [Internet]. 2020 Sep 3 [cited 2021 Jun 5];42(4):853-4. Available from:

https://academic.oup.com/jpubhealth/article/42/4/853/5900208

40. Kinder M. Essential but undervalued: Millions of health care workers aren't getting the pay or respect they deserve in the COVID-19 pandemic [Internet]. Brookings. Brookings; 2020 [cited 2021 Jun 5]. Available from:

https://www.brookings.edu/research/essential-but-undervalued-millions-of-health-care-workers-arent-getting-the-payor-respect-they-deserve-in-the-covid-19-pandemic/

41. Kang L, Li Y, Hu S, Chen M, Yang C, Yang BX, et al. The mental health of medical workers in Wuhan, China dealing with the 2019 novel coronavirus. The Lancet Psychiatry [Internet]. 2020 Mar [cited 2021 Jun 5];7(3):e14. Available from: https://www.thelancet.com/journals/lanpsy/article/PIIS2215-0366(20)30047-X/fulltext

42. Show Me the Science [Internet]. 2021 [cited 2021 Jun 5]. Available from: https://www.cdc.gov/handwashing/show-methe-science.html 
43. Haston JC, Miller GF, Berendes D, Andújar A, Marshall B, Cope J, et al. Characteristics Associated with Adults Remembering to Wash Hands in Multiple Situations Before and During the COVID-19 Pandemic - United States, October 2019 and June 2020. MMWR Morbidity and Mortality Weekly Report [Internet]. 2020 Oct 9 [cited 2021 Jun 5];69(40):1443-9. Available from: https://www.cdc.gov/mmwr/volumes/69/wr/mm6940a2.htm?s_cid=mm6940a2_w

44. Albarrak Al, Mohammed R, Al Elayan A, Al Fawaz F, Al Masry M, Al Shammari M, et al. Middle East Respiratory Syndrome (MERS): Comparing the knowledge, attitude and practices of different health care workers. Journal of Infection and Public Health [Internet]. 2021 Jan [cited 2021 Jun 5];14(1):89-96. Available from:

https://pubmed.ncbi.nlm.nih.gov/31431424/

45. Saqlain M, Munir MM, Rehman SU, Gulzar A, Naz S, Ahmed Z, et al. Knowledge, attitude, practice and perceived barriers among healthcare workers regarding COVID-19: a cross-sectional survey from Pakistan. Journal of Hospital Infection [Internet]. 2020 Jul [cited 2021 Jun 5];105(3):419-23. Available from:

https://pubmed.ncbi.nlm.nih.gov/32437822/

46. Curtis V, Schmidt W, Luby S, Florez R, Touré O, Biran A. Hygiene: new hopes, new horizons. The Lancet Infectious Diseases [Internet]. 2011 Apr [cited 2021 Jun 5];11(4):312-21. Available from:

https://pubmed.ncbi.nlm.nih.gov/21453872/

47. Wu B, Zhao Y, Xu D, Wang Y, Niu N, Zhang M, et al. Factors associated with nurses' willingness to participate in care of patients with COVID-19: A survey in China. Journal of Nursing Management [Internet]. 2020 Sep 12 [cited 2021 Jun 5];28(7):1704-12. Available from: https://onlinelibrary.wiley.com/doi/10.1111/jonm.13126

48. Lord H, Loveday C, Moxham L, Fernandez R. Effective communication is key to intensive care nurses' willingness to provide nursing care amidst the COVID-19 pandemic. Intensive and Critical Care Nursing [Internet]. 2021 Feb [cited 2021 Jun 5];62:102946. Available from: https://www.ncbi.nlm.nih.gov/pmc/articles/PMC7528824/

49. Rafi MdA, Hasan MT, Azad DT, Alam SF, Podder V, Hossain S, et al. Willingness to work during initial lockdown due to COVID-19 pandemic: Study based on an online survey among physicians of Bangladesh. Pakpour AH, editor. PLOS ONE [Internet]. 2021 Feb 9 [cited 2021 Jun 5];16(2):e0245885. Available from:

https://journals.plos.org/plosone/article?id=10.1371/journal.pone.0245885

50. Ma X, He Z, Wang Y, Jiang L, Xu Y, Qian C, et al. Knowledge and attitudes of healthcare workers in Chinese intensive care units regarding 2009 H1N1 influenza pandemic. BMC Infectious Diseases [Internet]. 2011 Jan 25 [cited 2021 Jun 5];11(1). Available from: https://bmcinfectdis.biomedcentral.com/articles/10.1186/1471-2334-11-24

51. Tebruegge M, Pantazidou A, Ritz N, Connell T, Bryant P, Donath S, et al. Perception, attitudes and knowledge regarding the 2009 swine-origin influenza A (H1N1) virus pandemic among health-care workers in Australia. Journal of Paediatrics and Child Health [Internet]. 2010 Aug 25 [cited 2021 Jun 5];46(11):673-9. Available from: https://pubmed.ncbi.nlm.nih.gov/20796180/

52. Imai H, Matsuishi K, Ito A, Mouri K, Kitamura N, Akimoto K, et al. Factors associated with motivation and hesitation to work among health professionals during a public crisis: a cross sectional study of hospital workers in Japan during the pandemic (H1N1) 2009. BMC Public Health [Internet]. 2010 Nov 4 [cited 2021 Jun 5];10(1). Available from:

https://pubmed.ncbi.nlm.nih.gov/21050482/

53. Bell MA, Dake JA, Price JH, Jordan TR, Rega P. A National Survey of Emergency Nurses and Avian Influenza Threat. Journal of Emergency Nursing [Internet]. 2014 May [cited 2021 Jun 5];40(3):212-7. Available from: https://pubmed.ncbi.nlm.nih.gov/23099013/

54. Tzeng H-M, Yin C-Y. Nurses' Fears and Professional Obligations Concerning Possible Human-to-Human Avian Flu. Nursing Ethics [Internet]. 2006 Sep [cited 2021 Jun 5];13(5):455-70. Available from: https://pubmed.ncbi.nlm.nih.gov/16961111/

55. Beresford L. Shift Fatigue in Healthcare Workers [Internet]. The-hospitalist.org. 2018 [cited 2021 Jun 5]. Available from: https://www.the-hospitalist.org/hospitalist/article/125427/shift-fatigue-healthcare-workers

Page $13 / 22$ 
56. Chen J, Li J, Cao B, Wang F, Luo L, Xu J. Mediating effects of self-efficacy, coping, burnout, and social support between job stress and mental health among young Chinese nurses. Journal of Advanced Nursing [Internet]. 2019 Oct 13 [cited 2021 Jun 5];76(1):163-73. Available from: https://onlinelibrary.wiley.com/doi/abs/10.1111/jan.14208

57. Saravanabavan L, Sivakumar MN, Hisham M. Stress and Burnout among Intensive Care Unit Healthcare Professionals in an Indian Tertiary Care Hospital. Indian journal of critical care medicine: peer-reviewed, official publication of Indian Society of Critical Care Medicine [Internet]. 2019;23(10):462-6. Available from:

https://www.ncbi.nlm.nih.gov/pmc/articles/PMC6842838/

58. Al-Hunaishi W, Hoe VC, Chinna K. Factors associated with healthcare workers willingness to participate in disasters: a cross-sectional study in Sana'a, Yemen. BMJ Open [Internet]. 2019 Oct [cited 2021 Jun 5];9(10):e030547. Available from: https://bmjopen.bmj.com/content/9/10/e030547

59. Ip DKM, Lau EHY, Tam YH, So HC, Cowling BJ, Kwok HKH. Increases in absenteeism among health care workers in Hong Kong during influenza epidemics, 2004-2009. BMC Infectious Diseases [Internet]. 2015 Dec [cited 2021 Jun 5];15(1). Available from: https://bmcinfectdis.biomedcentral.com/articles/10.1186/s12879-015-1316-y

60. Liu Q, Luo D, Haase JE, Guo Q, Wang XQ, Liu S, et al. The experiences of health-care providers during the COVID-19 crisis in China: a qualitative study. The Lancet Global Health [Internet]. 2020 Jun [cited 2021 Jun 5];8(6):e790-8. Available from: https://www.thelancet.com/journals/langlo/article/PIIS2214-109X(20)30204-7/fulltext

61. McMullan C, Brown GD, O'Sullivan D. Preparing to respond: Irish nurses' perceptions of preparedness for an influenza pandemic. International Emergency Nursing [Internet]. 2016 May [cited 2021 Jun 5];26:3-7. Available from: https://www.sciencedirect.com/science/article/abs/pii/S1755599X15001226?via\%3Dihub

62. Martin SD, Brown LM, Reid WM. Predictors of Nurses' Intentions to Work During the 2009 Influenza A (H1N1) Pandemic. AJN, American Journal of Nursing [Internet]. 2013 Dec [cited 2021 Jun 5];113(12):24-31. Available from: https://journals.Iww.com/ajnonline/Abstract/2013/12000/Predictors_of_Nurses_Intentions_to_Work_During.18.aspx

63. Henderson LN, Tulloch J. Incentives for retaining and motivating health workers in Pacific and Asian countries. Human Resources for Health [Internet]. 2008 Sep 15 [cited 2021 Jun 5];6(1). Available from: https://human-resourceshealth.biomedcentral.com/articles/10.1186/1478-4491-6-18

64. Nashwan AJ, Abujaber AA, Mohamed AS, Villar RC, Al-Jabry MM. Nurses' willingness to work with COVID-19 patients: The role of knowledge and attitude. Nursing Open [Internet]. 2020 Nov 5 [cited 2021 Jun 5];8(2):695-701. Available from: https://onlinelibrary.wiley.com/doi/10.1002/nop2.674

65. Wu B, Zhao Y, Xu D, Wang Y, Niu N, Zhang M, et al. Factors associated with nurses' willingness to participate in care of patients with COVID-19: A survey in China. Journal of Nursing Management [Internet]. 2020 Sep 12 [cited 2021 Jun 5];28(7):1704-12. Available from: https://onlinelibrary.wiley.com/doi/epdf/10.1111/jonm.13126

\section{Tables}

\section{Table 1}

\section{The Distribution of Demographic and Work Profile of the Nurse Respondents}

$(\mathrm{n}=137)$ 


\begin{tabular}{rrcc}
\hline \hline Gender & & $\mathrm{f}$ & $\%$ \\
\hline Male & 40 & 29.20 \\
\hline Female & 97 & 70.80
\end{tabular}

Age

\begin{tabular}{|c|c|c|}
\hline $20-25$ & 74 & 54.01 \\
\hline $26-30$ & 38 & 27.74 \\
\hline $31-35$ & 21 & 15.33 \\
\hline $36-40$ & 1 & 0.73 \\
\hline $41-45$ & 3 & 2.19 \\
\hline \multicolumn{3}{|l|}{ Marital Status } \\
\hline Single & 123 & 89.78 \\
\hline Married & 14 & 10.22 \\
\hline \multicolumn{3}{|l|}{ Highest Educational Attainment } \\
\hline College graduate & 124 & 90.51 \\
\hline Postgraduate & 13 & 9.49 \\
\hline \multicolumn{3}{|l|}{ Years of service as a hospital nurse } \\
\hline$<1$ year & 11 & 8.03 \\
\hline 1 to 3 & 89 & 64.96 \\
\hline 4 to 6 & 19 & 13.87 \\
\hline 7 to 10 & 15 & 10.95 \\
\hline more than 10 & 4 & 2.92 \\
\hline
\end{tabular}

Table 2

The Source of news updates on COVID-19

$(n=137)$ 


\begin{tabular}{lcc}
\hline \hline Sources of Information & $\mathrm{f}$ & $\%$ \\
\hline Internet & 136 & 99.27 \\
\hline Social Media (e.g. Facebook, Twitter, etc.) & 119 & 86.86 \\
\hline DOH/WHO & 114 & 83.21 \\
\hline TV & 91 & 66.42 \\
\hline Online Journals & 76 & 55.47 \\
\hline Conference/Seminars & 60 & 43.80 \\
\hline Radio & 46 & 33.58 \\
\hline Trainings & 44 & 32.12 \\
\hline Newspapers & 43 & 31.39 \\
\hline Books & 8 & 5.84 \\
\hline Magazines & 4 & 2.92 \\
\hline
\end{tabular}

Table 3.1

The Knowledge Level of the Respondents on COVID-19

$(n=137)$ 


\section{Knowledge}

Correct

COVID-19 is an infectious disease caused by a virus that is

$\begin{array}{llll}123 & 89.78 & 14 & 10.22\end{array}$

genetically related to the coronavirus responsible for the SARS

outbreak of 2003.

The average incubation period of COVID-19 is 5-6 days and can $\begin{array}{lllll}133 & 97.08 & 4 & 2.92\end{array}$ range from 1-14 days

The virus spreads through respiratory droplets from an infected $\begin{array}{lllll}131 & 95.62 & 6 & 4.38\end{array}$ person

Susceptibility to COVID-19 infection and its severity varies
according to the hosts; immune response and comorbid conditions

Anyone can get sick with COVID-19 and become seriously ill or die

$\begin{array}{llll}135 & 98.54 & 2 & 1.46\end{array}$

at any age, however, people aged 60 years and over, and those with

underlying medical problems like high blood pressure, heart and

lung problems, diabetes, obesity or cancer, are at higher risk of

developing serious illness.

About 80\% recover from the disease without needing hospital $104 \quad 75.91 \quad 33 \quad 24.09$ treatment and 15\% become seriously ill and require oxygen and 5\% become critically ill and need intensive care.

Dry cough, tiredness, and fever are the most common symptoms of $\quad \begin{array}{llll}122 & 89.05 & 15 & 10.95\end{array}$ COVID-19 infection

Body aches and pains, sore throat, diarrhea, loss of taste or smell $\quad \begin{array}{llll}90 & 65.69 & 47 & 34.31\end{array}$ are the less common in people infected with COVID-19

Difficulty breathing, shortness of breath, or chest pain are serious $\begin{array}{rrrrr}137 & 100.00 & 0 & 0.00\end{array}$ symptoms which warrant immediate medical attention

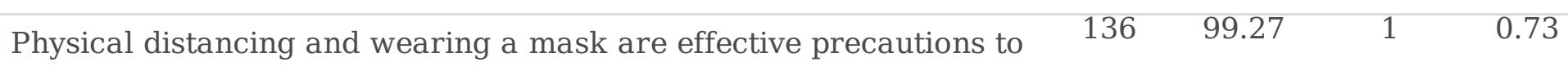
prevent spread of the virus

UV lamps, alcohol-based hand rubs, and washing with soap are the $\quad \begin{array}{llll}12 & 8.76 & 125 & 91.24\end{array}$ most effective ways to disinfect hands or other areas of the skin.

For hospitalized patients with COVID-19 whose symptoms are $\quad 8 \quad 5.84 \quad 129 \quad 94.16$ resolved, chest imaging is highly suggested in addition to clinical and/or laboratory assessment to inform the decision regarding discharge.

PCR test for SARS-COV2 will detect the causative agent of COVID50 36.50 $87 \quad 63.50$ 19 and confirm a past infection 
Optimal supportive care includes oxygen for all hospitalized COVID19 patients and those who are at risk for severe disease and more advanced respiratory support such as ventilation for patients who are critically ill.

Remdesivir, hydroxyquinone, ritonavir, and interferon regimens have been shown to offer some benefit in the treatment of COVID-19

Table 3.2

Distribution of the Respondents in terms of Knowledge Level

$$
(n=137)
$$

\begin{tabular}{lcc}
\hline \hline Knowledge Level & $\mathrm{f}$ & $\%$ \\
\hline Very Knowledgeable & 2 & 1.46 \\
\hline Knowledgeable & 109 & 79.56 \\
\hline Less Knowledgeable & 26 & 18.98 \\
\hline Not Knowledgeable At All & 0 & 0.00 \\
\hline Total & 137 & 100.00 \\
\hline
\end{tabular}

Legend: 13-15-Very Knowledgeable, 9-12- Knowledgeable, 5-8- Less Knowledgeable, 0-4-Not Knowledgeable At All

Table 4

The Type of Attitude towards COVID-19 of the Nurses

$$
(n=137)
$$




\begin{tabular}{|c|c|c|}
\hline Attitudes & $\begin{array}{l}\text { Weighted } \\
\text { Mean }\end{array}$ & Description \\
\hline $\begin{array}{l}\text { I believe that the severity of the COVID-19 situation in the Philippines will } \\
\text { smoothen }\end{array}$ & 3.45 & Favorable \\
\hline The hospitalized COVID-19 positive patients deserve the utmost level of care & 4.70 & $\begin{array}{c}\text { Very } \\
\text { Favorable }\end{array}$ \\
\hline I am confident to work in the frontlines during this pandemic & 4.17 & Favorable \\
\hline $\begin{array}{l}\text { I am confident that I will get full support from my family as a frontliner during } \\
\text { this pandemic }\end{array}$ & 4.18 & Favorable \\
\hline $\begin{array}{l}\text { I am very careful in observing health protocols because I am concerned that I } \\
\text { and/or any member of my family might get infected with COVID-19 }\end{array}$ & 4.78 & $\begin{array}{c}\text { Very } \\
\text { Favorable }\end{array}$ \\
\hline I am willing to comply with all the health protocols mandated by the IATF-DOH & 4.78 & $\begin{array}{c}\text { Very } \\
\text { Favorable }\end{array}$ \\
\hline If I will be infected, I am willing to isolate in an accredited health facility & 4.53 & $\begin{array}{c}\text { Very } \\
\text { Favorable }\end{array}$ \\
\hline I am willing to get myself complete COVID-19 vaccination doses & 4.71 & $\begin{array}{c}\text { Very } \\
\text { Favorable }\end{array}$ \\
\hline I am willing to convince my family members to get vaccinated & 4.70 & $\begin{array}{c}\text { Very } \\
\text { Favorable }\end{array}$ \\
\hline I will share the vaccination updates to my friends and relatives & 4.76 & $\begin{array}{c}\text { Very } \\
\text { Favorable }\end{array}$ \\
\hline Factor Average & 4.45 & $\begin{array}{c}\text { Very } \\
\text { Favorable }\end{array}$ \\
\hline
\end{tabular}

Legend: 1.00-1.79 -Very Unfavorable, 1.80-2.59 -Unfavorable, 2.60-3.39-Moderate, 3.40-4.19-Favorable, 4.20-5.00-Very Favorable

Table 5

The Extent of Practice towards COVID-19 of the Nurses

$(n=137)$ 


\begin{tabular}{|c|c|c|}
\hline Practices & $\begin{array}{l}\text { Weighted } \\
\text { Mean }\end{array}$ & Description \\
\hline I have been trained on how to handle COVID-19 patients. & 3.96 & Often \\
\hline $\begin{array}{l}\text { I always wear a medical mask when I leave my home and when I work my } \\
\text { shift. }\end{array}$ & 4.88 & Always \\
\hline $\begin{array}{l}\text { I wear complete PPEs when handling COVID-19 positive and suspected } \\
\text { patients. }\end{array}$ & 4.79 & Always \\
\hline I follow the proper protocol/s in donning and doffing my PPEs. & 4.80 & Always \\
\hline $\begin{array}{l}\text { I perform proper hand hygiene after handling patients and/or any } \\
\text { contaminated objects. }\end{array}$ & 4.91 & Always \\
\hline I avoid going to crowded places and social gatherings. & 4.34 & Always \\
\hline I strictly follow hospital infection control measures. & 4.82 & Always \\
\hline $\begin{array}{l}\text { I cooperate in contact tracing activities when exposed to COVID-19 positive } \\
\text { patients }\end{array}$ & 4.77 & Always \\
\hline I get myself tested when exposed to COVID-19 positive patients. & 4.60 & Always \\
\hline Factor Average & 4.65 & Always \\
\hline
\end{tabular}

Legend: 1.00-1.79 -Never, 1.80-2.59 -Seldom, 2.60-3.39-Sometimes, 3.40-4.19 Often, 4.20-5.00- Always

\section{Table 6}

The Extent of Willingness to Care of the Nurses for COVID-19 patients

$(n=137)$ 
In providing medical care to COVID-19 patients, I am willing to:

Establish goals and interventions (carry out physicians' orders, take vital signs,

4.85

Very

maintaining respiratory function, administer drugs, etc.)

Willing

Prevent spread of infection by adhering strictly to hospital policies of infection

4.87

Very

control

Willing

Monitor and follow-up care

4.84

Very

Willing

Factor Average

4.85

Very

Willing

In providing advice and emotional care to COVID-19 patients, I am willing to:

Help doctors in educating patients about their condition

$4.80 \quad$ Very

telp doctors in educating patients about their condition

Offer emotional support to patients and their families

4.77

Willing

Become more sensitive to the patients' needs

$4.80 \quad$ Very

Willing

Factor Average

4.79

Very

Willing

In undertaking the drawbacks as a nurse during the pandemic, I am willing to:

Continue to provide care when there is a surge of COVID-19 cases in our

4.61

Very institution

Willing

Work longer hours or extend shift in the hospital if necessary

$3.59 \quad$ Willing

Continue working despite the increased workload and have not considered

$3.53 \quad$ Willing

resignation or other occupation

\begin{tabular}{lcc}
\hline Factor Average & 3.91 & Willing \\
\hline Grand Mean & 4.52 & Very \\
& & Willing \\
\hline
\end{tabular}

Legend: 1.00-1.79 -Not at All, 1.80-2.59 -Less Willing, 2.60-3.39-Moderate, 3.40-4.19 Willing, 4.20-5.00Very Willing 
Table 7

The Pearson-rho correlation coefficients and p-values

\begin{tabular}{cc}
\hline \hline Predictors & $\begin{array}{c}\text { Predicted } \\
\text { Willingness }\end{array}$ \\
\hline Knowledge & 0.35 \\
$(p$-value $=0.23)$
\end{tabular}

*Relationship is Significant at Pearson $p$-value $<=0.05$ 